Some Aspects of Muscle Relaxants

(May and Baker Film)

This most interesting and skilfully prepared colour film was produced in the Department of Anaesthetics of St. Thomas's Hospital. The introduction is a short historical survey of the discovery and use of curare, illustrating Claude Bernard's experiment in a nerve-muscle preparation in the frog.

The remainder of the film is divided into three parts. In the first, entitled 'Pharmacology,' mention is made of d-tubocurarine, $\mathrm{C}$ ro, gallamine triethiodide (flaxedil) and mephanaesin, the site and mode of action of each drug being outlined. This is followed by a brief tabulation of the advantages and disadvantages of $d$-tubocurarine, flaxedil and C ro. By a clever series of animated diagrams the mode of action of these three compounds is illustrated, together with the mode of action of the anti-choline esterases.

Part two, dealing with the clinical uses of flaxedil, is cleverly produced, showing its effect on the conscious subject and on the anaesthetized patient. The best part of all is that showing the use of thiopentone and flaxedil for endotracheal intubation, with some magnificent views of the larynx during laryngoscopy and intubation. The only criticism one could make of the technique in this section is the post-operative intravenous administration of neostigmine and atropine in the same syringe to antagonize the residual curarization. Some pharmacologists maintain that this practice is not without danger as atropine first potentiates the harmful side-effects of neostigmine before antagonizing them. On these grounds it is said that the atropine should be given five minutes before the neostigmine. In the department, however, this practice has proved entirely satisfactory and no harmful results have ensued.

Part three deals with the use of flaxedil as an adjunct to electro-convulsive therapy, where it can be used to modify muscular activity and so protect the patient from injuries to bones and joints.

This is an excellent film which is strongly commended to lighten the burden of both undergraduates and of junior postgraduates.

\title{
ANNOTATION
}

\section{The Treatment of Acute Leukaemia}

Up to the present medicine has had little to offer in the treatment of acute leukaemia. Whilst the chronic forms can generally be controlledalthough not cured-by radiotherapy, nitrogen mustards, urethane or radioactive phosphorus $\left(P^{32}\right)$, these agents are ineffective in acute leukaemia and may even be deleterious.

Because of the lack of any specific treatment for acute leukaemia it has been the practice to administer a variety of drugs therapeutically active in other blood dyscrasias. Liver extracts, bone marrow extracts, pentnucleotide, pyridoxine and folic acid have all been used without benefit, and vitamin $B_{12}$ is also ineffective. Blood transfusions produce a transient and variable degree of symptomatic improvement, but do not alter the bone marrow. The use of exsanguination-transfusion has been advocated ${ }^{2}$ and, whilst this procedure does undoubtedly induce remissions, its effects are of relatively short duration and the discomforts to the patient and the technical difficulties involved render it an unpractical measure.

\section{Folic Acid Antagonists}

The discovery by Farber of Boston, in 1948, of the antileukaemic effects of antifolic acid compounds opened up a new line of approach to acute leukaemia. Their use arose from the observation that folic acid (pteroylglutamic acid, P.G.A.) in large amounts apparently exacerbates the leukaemic process. The effects of synthetic folic acid antagonists, which are structural analogues of P.G.A., were therefore investigated. The two most potent of these antagonists are 4-aminopteroylglutamic acid ('aminopterin') and 4amino-Nro-methylpteroylglutamic acid (' amethopterin'). They inhibit the growth promoting properties of P.G.A. for $L$. casei, and produce in animals clinical signs of folic acid deficiency. Their antagonism can be partially reversed by large amounts of folic acid, but more effectively by its conversion product, folinic acid (citrovorum factor). The action of the antagonists in leukaemia is probably to deprive the primitive rapidlygrowing leukaemic cells of essential P.G.A., their

(Continued on page 528) 
requirements of which are greater than are those of mature leucocytes. ${ }^{3}$ This deprivation is accomplished by the competitive substitution of the antagonists for P.G.A. in the cells' metabolism, a concept of drug action first postulated by Woods to explain the anti-streptococcal action of sulphanilamide. ${ }^{16}$ By this means leukaemic cells are prevented from utilizing P.G.A. for the synthesis of nucleoproteins.

Although the first reports of the use of folic acid antagonists in acute leukaemia seemed promising, subsequent accounts of large numbers of cases treated have proved somewhat disappointing. That these compounds are capable, in some cases, of favourably influencing the course of acute leukaemia is indubitable, and by their use significant haematological and clinical remissions have been brought about. But the remissions thus obtained are never permanent and in only a minority of cases can they be considered worthwhile. Published reports indicate that about one-third of all cases treated remit, and in only a few of these does the bone marrow revert to normal. Children are more responsive to treatment than are adults, and the subacute lymphoblastic leukaemias with an aleukaemic blood picture react better than do myeloblastic or leukaemic types. ${ }^{6}, 7,9$

The chief disadvantage of folic acid antagonists are their unpredictability of action, their extreme toxicity and the development of resistance to them. The amount of the drugs required varies from case to case within a wide range and serious toxic manifestations may necessitate their withdrawal before the bone marrow has been influenced. The principal toxic manifestations encountered are intractable haemorrhage, ulceration of the mouth and gastrointestinal tract, and bone marrow inhibition varying from reversible hypoplasia to complete aplasia. The resistance which emerges during treatment is restricted to the drugs' antileukaemic effects; sensitivity to their toxic effects remains, increasing the dangers of treatment. In addition, leukaemias resistant to one antifolic acid agent are also resistant to the others.

\section{Other Antimetabolites}

Other antimetabolites which might inhibit the development of leukaemic cells have been in- $\stackrel{\mathbb{D}}{\stackrel{2}{2}}$ vestigated. Gellhorn and Jones ${ }^{11}$ found desoxy- $\stackrel{c}{\Rightarrow}$ pyridoxine, an antagonist of pyridoxine, to be of no benefit in acute leukaemia. In any case, the need of the human for the vitamin has not been $\frac{\bar{c}}{\bar{s}}$ proved. Another antimetabolite, 2, 6, diamino- $\frac{\widehat{D}}{\mathrm{D}}$ purine, an antagonist of adenine, has been found antileukaemic in mice, 4,5 but its clinical use has not yet been reported.

\section{A.C.T.H, and Cortisone}

Adrenocortical hormones are known to affect $\frac{0}{7}$ blood-forming tissues, causing dissolution of lym- $\stackrel{\text { in }}{\text {. }}$ phoid tissue, lymphopenia and eosinopenia, and ${ }_{\omega}^{v}$ for this reason cortisone and A.C.T.H. might be $\vec{N}$ expected to have some therapeutic activity in $\stackrel{\infty}{\circ}$ leukaemias, especially of the lymphatic type. Ex- $\stackrel{\infty}{\circ}$ perience with these hormones in acute leukaemia has shown that they are capable of inducing $\bigcirc$ remissions, often of a marked degree, in a varying $\frac{?}{0}$ proportion of cases, irrespective of the cell $\stackrel{\Phi}{-}$ type. ${ }^{8}, 13,14$ But the clinical results are dif $\overrightarrow{0}$ appointing, relapse following within a few weets.of cessation of therapy, and usually accompaniedi by resistance to further treatment. As large amounts of the hormones are required, the incidence of side-effects is high. Farber ${ }^{10}$ is of the $\frac{2}{\mathbb{Q}}$ opinion that the results of hormone therapy are $\stackrel{2}{\vec{A}}$ inferior to those of antifolic acid therapy and $\frac{0}{3}$ suggests that the two forms of treatment might with benefit be combined.

\section{Streptomycin Residues}

The report by Barnard ${ }^{1}$ that certain fermentation by-products of Streptomyces griseus cause clinical $\stackrel{\circ}{\circ}$ remissions of acute leukaemia has not yet been

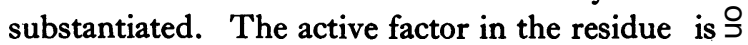
thought to be residual antibiotics, which act by $\frac{D}{0}$ suppressing the coli-aerogenes intestinal flora. In support of this Barnard claims that any of the streptomyces-derived antibiotics, given so as to $\stackrel{N}{N}$ suppress the normal intestinal flora, will cause im- $\omega$ provement until the emergence of streptomycinresistant strains, but the bone marrow remains $\frac{0}{D}$ unaltered.

\section{Conclusion}

Although agents have recently been introduced 
which can favourably influence acute leukaemia for short periods, they cannot be regarded as other than temporizing measures in the treatment of this disease. And until some knowledge is gained of the pathogenesis of acute leukaemia its treatment is likely to remain symptomatic and largely empirical. Evidence has recently been presented suggesting that in leukaemia there is a lack of specific myeloid or lymphoid maturing factors in the plasma. ${ }^{12}, 15$ If this is confirmed, there is hope that, even in the absence of knowledge of the fundamental cause of the leucopoietic derangement, some type of replacement therapy may emerge which will return the blood of leukaemic patients to normal. Acute leukaemia may prove analogous to pernicious anaemia in this respect.

\section{Ellis Dresner, M.D., \\ Department of Medicine, Postgraduate Medical School of London.}

\section{REFERENCES}

I. BARNARD, R. D. (1951), Lancet, i, I 157.

2. BESSIS, M. (1949), Blood, 4, 324.

3. BETHEL, F. H.; and SWENDSEID, M. E. (1946), f. Clin. Invest., 25, 917.

4. BURCHENAL, J. H., JOHNSON, S. F., BURCHENAL, J. R., KUSHIDA, M. N., ROBINSON, E., and STOCK, C. C. (1949), Proc. Soc. Exper. Biol. Med., 7I, 38I.

5. BURCHENAL, J. H., WEBBER, L. F., MEIGGS, G. M., and BIEDLER, J. L. (1951), Blood, 6, 337.

6. DACIE, J. V., DRESNER, E., MOLLIN, D. L., and WHITE, J. C. (1950), Brit. Med. ̈., i, 1447.

7. DACIE, J. V., DRESNER, E., MOLLIN, D. L., and WHITE, J. C. (195I), Ibid., i, 784 .
8. DAMESHEK, W., SAUNDERS, R. H., ZANNOS, L. (1950), Bull. New Engl. Med. Centre, I2, I I.

9. DRESNER, E. (1950), Quart. F. Med., I9, 339.

Io. FARBER, S., DOWNING, V., KENNEDY, B. H., SWACHMAN, H., and TOCH, R. (1950), Blood, 5, 787.

II. GELLHORN, A., and JONES, L. O. (1949), Ibid., 4, 60.

I 2. ISRAELS, M. G. C. (1940), 7. Path. Bact., 5I, 235.

13. SPIES, T. D., STONE, R. E., LOPEZ, G. G., MILANES, F., TOCA, R. L., and REBOREDO, A. (1950), Lancet, 2, $24 \mathrm{I}$

14. STICKNEY, J. M., HECK, F. J., and WATKINS, C. H. (1950), Proc. Mayo Clin., 25, 488.

15. WHITBY, L. E. H. (1951), f. Clin. Path., 4, 129.

16. WOODS, D. D. (1940), Brit. F. Exp. Path., 21, 74.

\section{BOOK REVIEWS}

\section{SPLEEN PUNCTURE}

By Sven Moeschlin (Zurich). Translated by A.

PINEY, M.D. Pp. xi +229 , with 55 illustrations.

London: William Heinemann. 195I. 30s.

Spleen puncture, as an aid to clinical diagnosis, has been overlooked possibly because of the danger of serious complications. Dr. Moeschlin's experience of over 300 such punctures proves that in skilled hands serious complications can be avoided; the only ill effects noted in his series being a slight ' stitch' in eight cases. The book is a discussion of the results of these punctures which were personally carried out by him at the Zurich Clinic between I 939 and 1949.

In the first part of the book the author describes his technique of puncture and aftercare of the patient. Then follow 30 pages, with many illustrations, describing his classification of the cells found in spleen smears. This would seem to be unnecessarily complicated and it is doubtful whether the division of reticulo-endothelial cells into some ten types on purely morphological grounds serves any useful purpose. In this section the author frequently digresses and it is somewhat disconcerting to find under the heading of mature granulocytes that apart from the first sentence, it is the monocytic series which is really being discussed.

The second and larger part of the book is devoted to the changes found in splenic smears in various diseases. These are based on the author's personal experience, but reference is made to the published literature on the subject. Bone marrow and gland smear results are also given in many instances. The text is illustrated by photomicrographs. Short accounts of illustrative and interesting cases add to the value of the text. A rather long and tedious section on mitoses is somewhat out of place in a work of this type.

The translator has done his work well and apart from a few rather awkward sentences the book is easy to read.

J.W.S. 